\title{
BALANÇO ENERGÉTICO COMPARATIVO PARA ROTAS DE ESCOAMENTO DE SOJA
}

\section{MARCO A. M. BIAGGIONI ${ }^{1}$, FÁBIO C. BOVOLENTA ${ }^{2}$}

RESUMO: O presente trabalho objetivou analisar o fluxo energético no escoamento de soja da região Centro-Oeste do Brasil, considerando as rotas atualmente existentes, mais precisamente, do município de Rio Verde -GO até o porto de Santos - SP, visto que este é um grande polo exportador de granéis sólidos. Foram selecionadas duas rotas para a análise, uma contemplando a multimodalidade, ou seja, os modais rodoviário, ferroviário e hidroviário, e outra, uma única modalidade, o modal rodoviário. A conversão dos fatores físicos e operacionais em unidades energéticas foi realizada por meio de coeficientes energéticos levantados junto à literatura. Os resultados obtidos indicaram, pela rota 1 multimodal, um gasto energético específico maior para o modal rodoviário $\left(0,50 \mathrm{MJ} \mathrm{km}^{-1} \mathrm{t}^{-1}\right)$, seguido pelo modal ferroviário $\left(0,42 \mathrm{MJ} \mathrm{km}^{-1} \mathrm{t}^{-1}\right) \mathrm{e}$, em terceiro, o modal hidroviário $\left(0,22 \mathrm{MJ} \mathrm{km}^{-1} \mathrm{t}^{-1}\right)$. Pela rota 2 , unimodal rodoviário, o resultado indicou 0,50 $\mathrm{MJ} \mathrm{km}^{-1} \mathrm{t}^{-1}$. Nas participações de energia apresentadas, comparando as rotas $1 \mathrm{e} 2$, a que apresentou maior gasto energético específico total foi a rota $2\left(0,50 \mathrm{MJ} \mathrm{km}^{-1} \mathrm{t}^{-1}\right)$, seguida pela rota $1\left(0,34 \mathrm{MJ} \mathrm{km}^{-1} \mathrm{t}^{-1}\right)$.

PALAVRAS-CHAVE: transporte multimodal, rodovia, ferrovia, hidrovia, escoamento de soja, balanço energético.

\section{COMPARATIVE ENERGY ANALYSIS FOR SOYBEAN JOURNEY TRANSPORT}

\begin{abstract}
The present work had as goal to study the energy flows about routes for soybean transport, at the Brazil middle-west region, from Rio Verde (GO) to Santos (SP). Two routes for analysis had been selected: a multimodality way (highway, railway and waterway modals), and one modality way (highway modal). The conversion of physical and operational factors in energetic unities was obtained in literature, by means energy coefficients. Initially, comparing the results obtained into multimodal way (route-1), the highway transport presented the largest energy expense specific $\left(0.50 \mathrm{MJ} \mathrm{km}^{-1} \mathrm{t}^{-1}\right)$, followed by railway $\left(0.42 \mathrm{MJ} \mathrm{km}^{-1} \mathrm{t}^{-1}\right)$ and, finally, the waterway $\left(0.22 \mathrm{MJ} \mathrm{km}^{-1} \mathrm{t}^{-1}\right)$. For route-2 (one modal transport), the results indicated $0.50 \mathrm{MJ} \mathrm{km}^{-1} \mathrm{t}^{-1}$ by the highway. Comparing the analyzed routes, the total specific energy spends by the route- 2 $\left(0.50 \mathrm{MJ} \mathrm{km}^{-1} \mathrm{t}^{-1}\right)$ it was greater than that one by route-1 $\left(0.34 \mathrm{MJ} \mathrm{km}^{-1} \mathrm{t}^{-1}\right)$.
\end{abstract}

KEYWORDS: multimodal transport, highway, railway, waterway, soybean transport, energy analysis.

\section{INTRODUÇÃO}

A soja e seus derivados são os produtos que mais geram volume de exportação no País, sendo o Brasil o segundo maior exportador do mundo. Em 2003, o Brasil produziu 51,5 milhões de toneladas e exportou quase 20 milhões, tendo sofrido um volume de perdas da ordem de 3,5 milhões de toneladas na fase de pós-colheita (IBGE, 2006a). Excluindo o volume exportado e a quantidade perdida do produto, houve uma disponibilidade interna de 26,2 milhões de toneladas que foi utilizada, em grande parte, pela indústria, para a produção de derivados de soja, como óleo, farelo, etc. A União Europeia foi a maior compradora da soja brasileira no ano de 2003, embora a China venha aumentando sua participação desde o ano 2000.

\footnotetext{
${ }^{1}$ Eng ${ }^{\mathrm{o}}$ Agrônomo, Prof. Doutor, Departamento de Engenharia Rural, FCA/UNESP, Botucatu - SP, biaggioni@ fca.unesp.br.

2 Tecnólogo em Construção Naval, Doutorando do Programa de Pós-Graduação em Energia na Agricultura, FCA/UNESP, Botucatu SP, Prof. Associado do Departamento de Navegação da FATEC, Jaú - SP, fabiobovolenta@ fca.unesp.br.

Recebido pelo Conselho Editorial em: 17-10-2007

Aprovado pelo Conselho Editorial em: 21-5-2010
} 
Os aumentos da produtividade e da produção de soja podem esbarrar, entretanto, na capacidade de escoamento do País, que tem investido menos do que as previsões e as necessidades estimadas pelas empresas.

CAIXETA FILHO \& GAMEIRO (2001) destacaram que, numa época de pico, os caminhões existentes no mercado não são suficientes para atender a toda movimentação de soja e de outras commodities. A iniciativa privada tem feito investimentos no sentido de melhorar a infraestrutura, de tal forma a diversificar alternativas para o seu escoamento, como exemplos têm-se a Ferronorte e as hidrovias do Madeira e do Tietê-Paraná.

FIGUEIREDO et al. (2003), por sua vez, enfatizaram que o Brasil vive uma situação peculiar no que diz respeito a seu sistema de transporte. Se, por um lado, verifica-se um enorme esforço de modernização por parte dos embarcadores e transportadores, por outro, convive-se com grandes deficiências na infraestrutura e no aparato regulatório. Como consequência, observam-se enormes distorções na matriz de transporte brasileira, dominada por um modal rodoviário altamente deficiente e que contribui para o estabelecimento de substanciais barreiras ao aumento da eficiência e melhoria dos serviços oferecidos.

A multimodalidade de transportes mostra-se como opção para a logística no escoamento da soja. Por causa de características diferentes entre os modais alternativos, como custos e outros aspectos qualitativos, pode ser economicamente desejável que entre a origem e o destino de determinada mercadoria seja utilizada mais de uma modalidade de transporte, com o uso de vantagens inerentes a cada uma delas, o que resultará num serviço de menor custo e de melhor qualidade.

BRAVIN (2001), analisando o transporte multimodal na região da hidrovia Tietê-Paraná, utilizou um modelo composto por rodovia, hidrovia e ferrovia (rodo-hidro-ferroviário). Neste trabalho, analisou-se o embarque de 2.400 toneladas de soja, que seguiram em caminhões de Rio Verde - GO até o terminal de São Simão - GO, num total de $165 \mathrm{~km}$. A partir daí, o transporte foi por hidrovia, percorrendo uma distância total de $650 \mathrm{~km}$, até Pederneiras - SP, onde foi realizado o transbordo para vagões ferroviários graneleiros, percorrendo mais $560 \mathrm{~km}$ até Santos. O valor total gasto no deslocamento foi $19,00 \mathrm{US} \$ \mathrm{t}^{-1}$.

Em outro modelo, também apresentado por BRAVIN (2001), a soja foi transportada em caminhões graneleiros de Rio Verde - GO diretamente a Santos - SP, num total de $959 \mathrm{~km}$. O valor

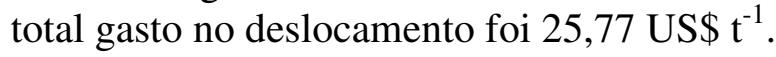

A energia consumida e produzida num sistema logístico depende de alguns fatores diretos e indiretos de operação. O óleo diesel, por exemplo, apresenta acentuada demanda de consumo energético, mas não é somente ele quem determina a contabilidade de energia total da logística de transporte multimodal da soja. Entre outros, estão o consumo de energia de lubrificante e graxa, o consumo de energia de máquinas e equipamentos, o consumo de energia de mão de obra, o consumo de energia elétrica e o consumo de energia para manutenção de rodovias, hidrovias e ferrovias.

Assim, a análise energética na logística de transporte multimodal pode revelar, de forma clara, a relação estrutural do sistema, mostrando o que pode ser eficiente ou ineficiente energeticamente.

COMITRE (1993) enfatiza que a análise energética, colocada em termos de balanço, tem sido objeto de estudo de pesquisadores no desenvolvimento de metodologias destinadas a contabilizar as energias produzidas (outputs) e as consumidas (inputs), em um determinado sistema de produção. Os fluxos energéticos inerentes a qualquer sistema expressam unidades calóricas por unidade de tempo, de massa, ou de área, traduzindo em análise de eficácia produtiva dos inputs calóricos daquele sistema. Esses são elementos fundamentais no cálculo da eficiência energética, representada por um índice que indica quantas unidades de energia são produzidas para cada unidade investida no processo produtivo. 
Tendo em vista a importância que o transporte de grãos representa para o agronegócio, este trabalho objetivou realizar uma análise energética de duas rotas de escoamento da soja da região Centro-Oeste do Brasil, uma contemplando a multimodalidade, ou seja, os modais rodoviário, hidroviário e ferroviário, e outra, uma única modalidade, o modal rodoviário.

\section{MATERIAL E MÉTODOS}

O estudo aqui descrito iniciou-se com a delimitação das rotas, modais e equipamentos envolvidos no transporte e movimentação de grãos, seguido pela definição dos fatores físicos envolvidos no trajeto e, $\operatorname{logo}$ após, a obtenção dos coeficientes energéticos.

Para cada modal estudado, adotou-se um "fator de equivalência de carga", deixando cada modalidade de transporte em condições semelhantes de carga transportada.

\section{Delimitação das rotas e modais de transporte}

\section{Rota multimodal (rota 1)}

Analisando o transporte multimodal na região da hidrovia Tietê-Paraná, adotou-se como ponto de partida o município de Rio Verde - GO. A escolha deste foi para possibilitar a análise de multimodalidade em um local que representa, hoje, um polo regional de desenvolvimento econômico-social, baseado na atividade agrícola, principalmente o cultivo da soja.

Assim, num modelo logístico composto por rodovia, hidrovia e ferrovia (rodo-hidroferroviário), propôs-se o embarque de 5.640 toneladas de soja (carga de referência), que seguiram em bitrens de Rio Verde - GO até o terminal de São Simão - GO, num total de $165 \mathrm{~km}$. A partir daí, o transporte foi por hidrovia, percorrendo uma distância total de $650 \mathrm{~km}$, até o terminal intermodal de Pederneiras - SP. Neste ponto, foi realizado o transbordo para vagões ferroviários graneleiros, os quais percorreram mais $560 \mathrm{~km}$ até Santos - SP.

\section{a) Modal rodoviário}

O transporte de Rio Verde - GO a São Simão - GO foi feito por modal rodoviário, percorrendo uma distância de $165 \mathrm{~km}$ (BRAVIN, 2001). Foi utilizado como padrão de transporte o bitrem graneleiro tracionado por um cavalo mecânico, com tara de 9,5 t, e dois semirreboques, com tara de 10,7 t. A vida útil do veículo é de 10 anos, com um consumo médio de $2,53 \mathrm{~km} \mathrm{~L}^{-1}$ de óleo diesel. Utiliza 26 pneus e dois pneus reservas com massa aproximada de $58 \mathrm{~kg}$ por pneu. Tem capacidade para transportar 38,5 t de carga líquida (SCANIA, 2006; GRUPO HUBNER, 2006; GOODYEAR, 2006; PAVAN, 2005).

O tempo aproximado do transporte é de $2 \mathrm{~h}$ 20min (BRAVIN, 2001), e o "fator de equivalência de carga" é de 146,5, isto é, são necessários 146,5 veículos para que seja atingida a carga de referência estipulada neste trabalho.

O transbordo para as barcaças, no terminal hidroviário de São Simão - GO, tem um fluxo operacional de $500 \mathrm{t} \mathrm{h}^{-1}$ (DALCOL, 2006). Foram utilizados dois tombadores hidráulicos, com $32 \mathrm{t}$ de massa cada, vida útil de 10 anos e dotados de um motor elétrico de 50 HP. Para o transporte horizontal, foi utilizada uma correia transportadora para 20 t de massa, vida útil de 10 anos e com motor elétrico de 75 HP (SAUR, 2006; DALCOL, 2006; TECNOMOAGEIRA, 2006; COPABO, 2006).

\section{b) Modal hidroviário}

O transporte feito por hidrovia percorreu uma distância de $650 \mathrm{~km}$ (BRAVIN, 2001). Foi utilizado um empurrador medindo $17 \mathrm{~m}$ de comprimento, boca de $7 \mathrm{~m}$, pontal de 2,5 m, calado de $1,7 \mathrm{~m}$, potência total de $900 \mathrm{HP}$, massa de $100 \mathrm{t}$ e vida útil de 30 anos. Completaram o comboio quatro barcaças com $60 \mathrm{~m}$ de comprimento, $11 \mathrm{~m}$ de boca, $3 \mathrm{~m}$ de pontal, 2,9 $\mathrm{m}$ de calado, massa de $1.200 \mathrm{t}$ (300 t cada chata) e vida útil de 30 anos. A capacidade total é de $5.640 \mathrm{t}$ de carga líquida 
(1.410 t por chata), e o consumo médio de óleo diesel do comboio hidroviário é de $0,18 \mathrm{~L} \mathrm{HP}^{-1} \mathrm{~h}^{-1}$ (BRAVIN, 2001; TAKAHASHI, 2006).

Ao longo da hidrovia, há 12 transposições por eclusas (Nova Avanhandava - SP, Promissão SP, Ibitinga - SP e Bariri - SP), feita por um operador em cada eclusa. Cada eclusa possui dois portões hidráulicos, um a montante, tipo esporão (duas folhas), com dois motores elétricos de $15 \mathrm{HP}$ cada um, 115 t de massa total, composto de material aço carbono, vida útil de 30 anos e tempo de operação de 3 minutos. Outro portão, a jusante, é do tipo vagão (uma folha) com um motor elétrico de $75 \mathrm{HP}, 115 \mathrm{t}$ de massa total, composto de material aço-carbono, vida útil de 30 anos e tempo de operação de 3 minutos (AES TIETÊ, 2006) ${ }^{\dagger}$.

O tempo aproximado total de viagem, de São Simão - GO a Pederneiras - SP, é de 96 horas (TAKAHASHI, 2006), e o "fator de equivalência" de carga é 1,0 (carga de referência).

No terminal hidroviário de Pederneiras - SP, o transbordo do comboio fluvial para o comboio ferroviário tem um fluxo operacional de $450 \mathrm{t} \mathrm{h}^{-1}$ (DALCOL, 2006). Foi feito por três sugadores pneumáticos de massa $100 \mathrm{~kg}$ cada um, vida útil de 10 anos, dotados de motores elétricos de $360 \mathrm{HP}$ cada um; uma correia transportadora de massa para $20 \mathrm{t}$, vida útil de 10 anos e um motor elétrico de 75 HP (DALCOL, 2006).

\section{c) Modal ferroviário}

O transporte de Pederneiras - SP até Santos - SP, feito por ferrovia, percorreu $560 \mathrm{~km}$ de distância (DALCOL, 2006). Foi realizado por quatro locomotivas, com consumo médio de óleo diesel de $7 \mathrm{~L} \mathrm{~km}^{-1}$. O comboio ferroviário completou-se com 50 vagões graneleiros, com capacidade total de $3.500 \mathrm{t}$ (70 t por vagão), uma tara de $1.500 \mathrm{t}$ e vida útil de 30 anos (DALCOL, 2006; COLENCI, 2006).

O tempo de transporte é de 48 horas, aproximadamente, até Santos (DALCOL, 2006) e o "fator de equivalência" de carga obtido foi de 1,61.

A descarga do comboio ferroviário tem fluxo operacional de $750 \mathrm{t} \mathrm{h}^{-1}$ (PINCELLI, 2006), sendo realizado por uma correia transportadora de massa para $20 \mathrm{t}$, vida útil de 10 anos, com motor de $100 \mathrm{HP}$, uma correia elevadora de massa para $30 \mathrm{t}$, vida útil de 10 anos, com motor elétrico de 75 HP (PINCELLI, 2006).

\section{Rota unimodal (rota 2)}

Para o transporte unimodal, adotou-se, como ponto de partida, o município de Rio Verde - GO. O transporte de Rio Verde - GO a Santos - SP foi feito por modal rodoviário percorrendo uma distância de 959 km (BRAVIN, 2001).

Utilizou-se de bitrens graneleiros, tracionados por cavalos mecânicos, com tara de 9,5 t e dois semirreboques com tara de 10,7 t. A vida útil do veículo é de 10 anos, com um consumo médio de $2,53 \mathrm{~km} \mathrm{~L}^{-1}$ de óleo diesel. Utilizou-se de 26 pneus e dois pneus reservas com massas aproximadas de $58 \mathrm{~kg}$ por pneu, e ele tem capacidade de transportar 38,5 t de carga líquida (SCANIA, 2006; GRUPO HUBNER, 2006; GOODYEAR, 2006; PAVAN, 2005).

O tempo aproximado de transporte é de 14 h (DALCOL, 2006), e o "fator de equivalência" de carga obtido foi de 146,5.

A descarga do bitrem graneleiro no porto de Santos tem fluxo operacional de $750 \mathrm{t} \mathrm{h}^{-1}$ (PINCELLI, 2006). Foi realizado por dois tombadores hidráulicos de massa para $32 \mathrm{t}$, vida útil de 10 anos, com motor elétrico de $50 \mathrm{HP}$; uma correia transportadora de massa para $20 \mathrm{t}$, vida útil de 10 anos, com motor de $100 \mathrm{HP}$; uma correia elevadora de massa para 30 t, vida útil de 10 anos, com motor de 75 HP (PINCELLI, 2006).

\footnotetext{
†Comunicação pessoal. “tiete.faleconosco@aes.com”
} 


\section{Fatores físicos envolvidos no trajeto}

No transporte rodoviário, de Rio Verde - GO a São Simão - GO, foram necessários um motorista, um ajudante, um bitrem graneleiro e 28 pneus (PAVAN, 2005). Em São Simão - GO, 18 operadores trabalharam no transbordo, sendo utilizados dois tombadores hidráulicos e uma correia transportadora (DALCOL, 2006).

Pela hidrovia, foram necessários nove tripulantes do comboio hidroviário, um empurrador, quatro barcaças graneleiras, 12 transposições por eclusas e quatro operadores de eclusa (DALCOL, 2006; TAKAHASHI, 2006). Para o transbordo em Pederneiras, foram necessários 12 operadores, três sugadores pneumáticos e uma correia transportadora.

Pela ferrovia, operaram as quatro locomotivas e 50 vagões, dois tripulantes do comboio ferroviário (DALCOL, 2006). Em Santos, na descarga, foram necessários 10 operadores, uma correia transportadora e uma correia elevadora (DALCOL, 2006; TAKAHASHI, 2006; ALEXANDRINO, 2006)

\section{Conversão dos fatores físicos em energéticos}

Os principais fatores físicos envolvidos nas rotas e modais descritos foram máquinas elétricas, com os respectivos consumos de combustível, lubrificantes e graxas, mão de obra utilizada, por operação, além da energia indireta de máquinas e equipamentos, e energia indireta de manutenção de vias.

\section{Energia do tipo direta de fonte industrial, sob a forma elétrica}

Os equipamentos utilizados para os cálculos foram: tombador hidráulico, correia transportadora, correia elevadora, sugador pneumático e eclusa. A conversão foi feita por meio da eq.(1):

$$
\mathrm{EDIE}=0,745 \text { 3,6 P T F Ne }
$$

em que,

EDIE - energia do tipo direta de fonte industrial sob a forma elétrica, MJ;

$\mathrm{P}$ - potência, HP;

T - tempo de utilização, h;

$\mathrm{F}$ - fator de equivalência de carga, e

$\mathrm{Ne}$ - número de equipamentos.

\section{Energia do tipo direta de fonte fóssil, sob a forma de combustíveis e lubrificantes}

Neste item, há a conversão dos consumos totais de combustíveis e lubrificantes. Para a obtenção dos conteúdos energéticos, foi utilizado o fator de 1,14, que corresponde a $14 \%$ do gasto energético utilizado para a produção do óleo diesel, óleo lubrificante e graxa. Os coeficientes energéticos adotados, conforme ROMERO (2005), foram: óleo diesel 40,87 $\mathrm{MJ} \mathrm{L}^{-1}$, para o óleo lubrificante $37,75 \mathrm{MJ} \mathrm{L}^{-1}$ e para graxa $43,37 \mathrm{MJ} \mathrm{kg}^{-1}$. A conversão foi feita através da eq.(2):

$$
\mathrm{EDF}=1,14 \mathrm{CE} \mathrm{CT} F
$$

em que,

EDF - energia do tipo direta de fonte fóssil, $\mathrm{MJ}$;

$\mathrm{CE}$ - coeficiente energético, $\mathrm{MJ} \mathrm{L}^{-1}$;

$\mathrm{CT}$ - consumo total, L, e

$\mathrm{F}$ - fator de equivalência de carga.

Para o consumo de óleo lubrificante e graxa, foram adotados os seguintes critérios:

\footnotetext{
† Comunicação pessoal. “mauri@kbrtec.com.br"
} 
- Bitrem: consumo de óleo lubrificante igual a 0,9\% do consumo de óleo diesel e consumo de graxa igual a $6,31 \%$ do consumo de óleo lubrificante. A densidade da graxa foi considerada como sendo de $0,88 \mathrm{t} \mathrm{m}^{-3}$. Os percentuais de consumo do óleo diesel, óleo lubrificante e graxa foram calculados segundo dados fornecidos em De LUCCA (2006).

- Comboio hidroviário: consumo de óleo lubrificante igual a 1,8\% do consumo de óleo diesel. O percentual de consumo do óleo lubrificante seguiu os mesmos padrões de consumo dos motores de bitrens, apenas multiplicado por dois, pois em empurradores, são comumente instalados dois motores, e os mesmos são apenas adaptados às condições de navegabilidade. Também não foi considerado o consumo de graxa, visto que, segundo TAKAHASHI (2006), o valor é desprezível.

- Comboio ferroviário: consumo de óleo lubrificante igual a 0,04\% do consumo de óleo diesel e consumo de graxa desprezível (EIRAS, 2006).

\section{Energia do tipo direta de fonte biológica, sob a forma de mão de obra}

O procedimento para os cálculos do dispêndio energético relativo à mão de obra seguiu o que foi proposto por CARVALHO (1974, apud CAMPOS, 2001), que utilizou um equipamento considerado de boa precisão, o respirômetro, em seus trabalhos. Sendo assim, optou-se por utilizar o valor de $386,40 \mathrm{~kJ} \mathrm{~h}^{-1}$ ou $0,3864 \mathrm{MJ} \mathrm{h}^{-1}$, como padrão para todas as atividades envolvendo mão de obra. A conversão foi feita por meio da eq.(3):

$$
\mathrm{EDBMO}=0,3864 \mathrm{~N} \mathrm{~T} \mathrm{~F}
$$

em que,

EDBMO - energia do tipo direta de fonte biológica sob a forma de mão de obra, MJ;

$\mathrm{N}$ - número de trabalhadores;

$\mathrm{T}$ - tempo de trabalho, h, e

F - fator de equivalência de carga.

\section{Energia do tipo indireta de fonte industrial, sob a forma de máquinas e equipamentos}

O procedimento adotado para os cálculos da depreciação energética relativa às máquinas e equipamentos seguiu as recomendações de MOREIRA et al. (2005). Os cálculos de energia indireta embutida nas máquinas e implementos foram realizados conforme as eqs.(4), (5), (6), (7) e (8):

$$
\begin{aligned}
& \text { EIIME }=\left[(a+b+c+d) V^{-1}\right] T F ~ N e \\
& a=\text { mme CE } \\
& b=0,05 a \\
& c=n p m p C E \\
& d=0,12(a+b+c)
\end{aligned}
$$

em que,

EIIME - energia indireta industrial de máquinas e equipamentos, $\mathrm{MJ}$;

mme - massa das máquinas e equipamentos, $\mathrm{kg}$;

$\mathrm{CE}$ - coeficiente energético de referência, $\mathrm{MJ} \mathrm{kg}^{-1}$;

np - número de pneus;

$\mathrm{mp}$ - massa do pneu, $\mathrm{kg}$;

VU - vida útil, h;

$\mathrm{T}$ - tempo de trabalho, h;

$\mathrm{F}$ - fator de equivalência de carga, e

$\mathrm{Ne}$ - número de equipamentos.

Na Tabela 1, apresentam-se os coeficientes energéticos utilizados nas eqs.(5) e (6). 
TABELA 1. Coeficientes energéticos $\left(\mathrm{MJ} \mathrm{kg}^{-1}\right)$ correspondentes a cada tipo de material utilizado nas depreciações energéticas de máquinas ou equipamentos. Energetic coefficients corresponding to each type of material used in the energy depreciation of machinery or equipment.

\begin{tabular}{llc}
\hline Máquinas e Equipamentos & Material & Coeficiente Energético \\
\hline Bitrem - cavalo mecânico & aço & 62,79 \\
Bitrem - semirreboques & aço & 62,79 \\
Bitrem - semirreboque & madeira & 10,47 \\
Comboio fluvial & aço & 62,79 \\
Comboio ferroviário & aço & 62,79 \\
Tombador hidráulico & aço & 62,79 \\
Sugador pneumático & borracha & 85,81 \\
Correia transportadora & aço & 62,79 \\
Correia transportadora & borracha & 85,81 \\
Correia elevadora & aço & 62,79 \\
Moega & aço & 62,79 \\
Portão de eclusa & aço & 62,79 \\
Pneu & borracha & 85,81 \\
\hline
\end{tabular}

Energia do tipo indireta de fonte industrial, sob a forma de manutenção de rodovias, hidrovias e ferrovias

O procedimento adotado seguiu o que foi proposto por POZO (2002). Para os cálculos foi utilizada a depreciação monetária considerando o valor residual igual a zero. $\mathrm{O}$ valor monetário foi convertido em energia pela "intensidade energética", isto é, a energia consumida no Brasil, em 2004, dividida pelo produto interno bruto em 2004.

A energia consumida no Brasil, em 2004, foi de 8 trilhões de MJ (BRASIL, 2006), enquanto o produto interno bruto do Brasil foi de 1,767 trilhão de Reais (IBGE, 2006b).

$\mathrm{O}$ custo de implantação dos trechos, rodoviário $\left(941.600 \mathrm{R} \$ \mathrm{~km}^{-1}\right)$, hidroviário (72.760 R \$ km ${ }^{-1}$ ) e ferroviário (2.996.000 R $\$ \mathrm{~km}^{-1}$ ), seguiu o que foi indicado por BORGES (2006).

Para a obtenção dos valores das quantidades de veículos que trafegam por hora, em cada modal considerado, adotou-se: pela rodovia - 104,17 (MACHADO, 2005), ferrovia - 0,34 (EIRAS, 2006) e hidrovia - 0,083 (AES TIÊTE, 2006).

Assim, a energia envolvida na manutenção dos trechos pode ser obtida pelas eqs. (9) e (10):

$$
\mathrm{EIIM}=\mathrm{IE} \mathrm{F}\left\{\left[\text { CIT D) } \mathrm{VU}^{-1}\right] \mathrm{Vh}^{-1}\right.
$$

$\mathrm{IE}=\mathrm{ECB} \mathrm{PIB}^{-1}$

em que,

EIIM - energia indireta industrial de manutenção, MJ;

$\mathrm{IE}$ - intensidade energética, $\mathrm{MJ} \mathrm{R}^{-1}$;

F - fator de equivalência de carga, veículos;

ECB - energia consumida no Brasil em 2004, MJ;

PIB - produto interno bruto do Brasil em 2004, R \$;

CIT - custo de implantação do trecho, $\mathrm{R} \$ \mathrm{~km}^{-1}$;

D - distância do trecho, km;

VU - vida útil, h, e

Vh - veículos por hora. 


\section{RESULTADOS E DISCUSSÃO}

\section{Análise comparativa entre os modais da rota 1}

Nas demandas de energia, por tipo, fonte e forma, na rota 1 multimodal, de Rio Verde - GO a Santos - SP, apresentadas na Tabela 2, pode-se verificar maior participação de energia dos tipos direta e indireta, apresentada pelo modal ferroviário, seguido do hidroviário e, logo após, o rodoviário.

O consumo de energia do tipo direta de fonte elétrica obtida pelo modal hidroviário representou a maior participação $(81,50 \%)$, seguida pelo modal rodoviário (11\%) e, em terceiro, o modal ferroviário $(7,50 \%)$. Tal resultado pode ser explicado pelo alto dispêndio apresentado no transbordo em Pederneiras - SP.

TABELA 2. Entrada de energia, por tipo, fonte e forma, em MJ, na rota 1 multimodal de Rio Verde - GO) a Santos - SP. Energy input, by type, source and form, in MJ, for multimodal transport - route 1-, from Rio Verde (GO) to Santos (SP).

\begin{tabular}{|c|c|c|c|c|}
\hline TIPO, fonte e forma & Rodoviário $\frac{1}{1}$ & $\frac{\text { ais }}{\text { oviárioFerrovi }}$ & o Total & \\
\hline ENERGIA DIRETA & $454.796,55$ & $776.021,16$ & $1.180 .232,26$ & $2.411 .049,97$ \\
\hline Elétrica & $\overline{5.294,50}$ & $38.983,28$ & $3.528,90$ & $47.806,68$ \\
\hline$\overline{\text { Tombador hidráulico }}$ & $\overline{3.025,43}$ & - & - & $3.025,43$ \\
\hline Correia transportadora & $2.269,07$ & $2.520,41$ & $2.016,52$ & $6.806,00$ \\
\hline Correia elevadora & - & - & $1.512,39$ & $1.512,39$ \\
\hline Portão eclusa à jusante & - & 120,69 & - & 120,69 \\
\hline Portão eclusa a montante & - & 48,28 & - & 48,28 \\
\hline Sugador pneumático & - & $36.296,90$ & - & $36.296,90$ \\
\hline Fóssil & $\underline{449.159,80}$ & $736.645,47$ & $1.176 .616,39$ & $2.362 .421,66$ \\
\hline Óleo diesel & $445.172,07$ & $724.595,00$ & $1.176 .200,67$ & $2.345 .967,74$ \\
\hline Lubrificante & $3.719,73$ & $12.049,80$ & 415,72 & $16.185,25$ \\
\hline Graxa & 268,00 & - & - & 268,00 \\
\hline Biológica & $\underline{342,25}$ & $\underline{392,41}$ & $\underline{86,97}$ & $\underline{821,63}$ \\
\hline Mão de obra & $\overline{342,25}$ & $\overline{392,41}$ & $\overline{86,97}$ & $\overline{821,63}$ \\
\hline ENERGIA INDIRETA & $10.881,24$ & 45.155,92 & $146.770,98$ & $202.808,14$ \\
\hline Industrial & $\underline{5.231,75}$ & $\underline{35.333,90}$ & $9.824,89$ & $\underline{50.390,54}$ \\
\hline$\overline{\text { Bitrem graneleiro }}$ & $\overline{4.420,82}$ & - & - & $4.420,82$ \\
\hline Tombador hidráulico & 608,56 & - & - & 608,56 \\
\hline Comboio hidroviário & - & $35.066,06$ & - & $35.066,06$ \\
\hline Portão eclusa à jusante & - & 19,39 & - & 19,39 \\
\hline Portão eclusa a montante & - & 19,39 & - & 19,39 \\
\hline Sugador pneumático & - & 4,33 & - & 4,33 \\
\hline Comboio ferroviário & - & - & $9.499,87$ & $9.499,87$ \\
\hline Correia transportadora & 202,37 & 224,79 & 134,89 & 562,05 \\
\hline Correia elevadora & - & - & 190,13 & 190,13 \\
\hline Industrial de manutenção & $5.649,49$ & $9.822,02$ & $136.946,09$ & $\underline{152.417 .60}$ \\
\hline Rodovia & $5.649,49$ & - & - & $5.649,49$ \\
\hline Hidrovia & - & $9.822,02$ & - & $9.822,02$ \\
\hline Ferrovia & - & - & $136.946,09$ & $136.946,09$ \\
\hline TOTAL & $465.677,79$ & $821.177,08$ & $1.327 .003,24$ & $2.613 .858,11$ \\
\hline $\begin{array}{l}\text { CONSUMO ESPECÍFICO } \\
{\left[\mathrm{MJ} \mathrm{km}^{-1} \mathrm{t}^{-1}\right]}\end{array}$ & 0,50 & 0,22 & 0,42 & 0,34 \\
\hline
\end{tabular}


Na participação de energia do tipo direta de fonte fóssil, o maior valor foi obtido pelo modal ferroviário $(49,80 \%)$, seguido pelo modal hidroviário $(31,18 \%)$ e, em terceiro, o modal rodoviário $(19,02 \%)$. Explica-se este resultado pelo alto consumo de óleo diesel $\left(0,036 \mathrm{~km} \mathrm{~L}^{-1}\right)$, em $560 \mathrm{~km}$ percorridos pelo comboio ferroviário.

Nas participações de energia do tipo indireta de fonte industrial, a obtida pelo modal hidroviário foi a maior $(70,12 \%)$, seguido pelo modal ferroviário $(19,50 \%)$ e, em terceiro, o modal rodoviário $(10,38 \%)$. Tais resultados podem ser explicados pela alta depreciação energética apresentada pelo comboio hidroviário.

Nas demandas de energia do tipo indireta de fonte industrial de manutenção, a maior participação apresentada foi pelo modal ferroviário $(89,85 \%)$, seguido do modal hidroviário $(6,44 \%)$ e, em terceiro, o modal rodoviário (2,65\%). Explica-se pelo alto custo de implantação do trecho ferroviário. A participação representada pela rodovia somente não foi maior que a hidrovia por conter um trecho de menor percurso.

Deve-se destacar, porém, o consumo específico de energia considerando a distância percorrida e a carga transportada. Nesta análise, foram obtidos os seguintes consumos: com maior gasto energético, o modal rodoviário $\left(0,50 \mathrm{MJ} \mathrm{km}^{-1} \mathrm{t}^{-1}\right)$, seguido pelo modal ferroviário $\left(0,42 \mathrm{MJ} \mathrm{km}^{-1} \mathrm{t}^{-1}\right) \mathrm{e}$, em terceiro, ficou o modal hidroviário $\left(0,22 \mathrm{MJ} \mathrm{km}^{-1} \mathrm{t}^{-1}\right)$.

\section{Modal rodoviário de Rio Verde - GO a Santos - SP, pela rota 2}

As demandas de energia, por tipo, fonte e forma, e participações percentuais nas operações de descarga e transporte rodoviário pela rota 1 unimodal, de Rio Verde - GO a Santos - SP, são apresentadas na Tabela 3. Analisando-se os dados, verifica-se maior participação de energia do tipo direta (97,63\%), representada pela fonte fóssil $(99,73 \%)$, sob a forma de óleo diesel $(99,12 \%)$. Tal demanda pode ser explicada pelo alto consumo de combustível $\left(2,53 \mathrm{~km} . \mathrm{L}^{-1}\right)$ apresentado pelo bitrem graneleiro, além do fato de necessitar envolver mais de 146 bitrens para transportar a carga estipulada (fator de equivalência).

A participação de energia do tipo indireta $(2,57 \%)$ foi baixa em relação à direta, sendo representada por um elevado número de máquinas e equipamentos $(42,93 \%)$ e energia industrial de manutenção da rodovia $(57,07 \%)$.

A participação de energia do tipo direta de fonte elétrica $(0,21 \%)$ foi baixa em relação à fonte fóssil, mas deve ser destacada, pois representa a energia consumida na operação de transbordo.

A fonte de energia biológica $(0,06 \%)$, representada pela mão de obra com 1,70 $\mathrm{MJ} \mathrm{km}^{-1}$, apresentou a menor participação. Explica-se por um pequeno dispêndio de energia liberada nas operações de mão de obra, mesmo com alto fator de equivalência de carga. ROMERO (2005), pesquisando o consumo de energia pela mão de obra (motorista de caminhão) em atividade de transporte de algodão dentro da propriedade, obteve valor de 2,50 $\mathrm{MJ} \mathrm{ha}^{-1}$. 
TABELA 3. Entrada de energia, por tipo, fonte e forma, em MJ, e participações percentuais na operação de transporte e descarga na rota 2 unimodal de Rio Verde - GO a Santos -SP. Energy input, by type, source and form, in MJ, and percentage in transport and unloading operations, for one modal transport - route 2 -, from Rio Verde (GO) to Santos (SP).

\begin{tabular}{lrr}
\hline TIPO, fonte e forma & \multicolumn{2}{c}{ Entradas de Energia } \\
\cline { 2 - 3 } & \multicolumn{1}{c}{$(\mathrm{MJ})$} & $\underline{72,81}$ \\
\hline ENERGIA DIRETA & $\underline{2.617 .512,21}$ & $\underline{0,21}$ \\
Elétrica & $\underline{5.510,61}$ & 36,36 \\
Tombador hidráulico & $2.003,86$ & 36,36 \\
Correia transportadora & $1.502,89$ & 27,28 \\
Correia elevadora & $\underline{2.610 .373,38}$ & $\underline{99,73}$ \\
Fóssil & $2.587 .281,09$ & 99,12 \\
Óleo diesel & $21.498,78$ & 0,82 \\
Lubrificante & $1.593,51$ & 0,06 \\
Graxa & $\underline{1.628,60}$ & $\underline{0,06}$ \\
Biológica & $1.628,60$ & 100,00 \\
Mão de obra & $\underline{63.554,37}$ & 2,37 \\
ENERGIA INDIRETA & $\underline{27.286,45}$ & $\underline{42,93}$ \\
Industrial & $26.560,45$ & 97,34 \\
Bitrem graneleiro & 403,01 & 1,48 \\
Tombador hidráulico & 134,04 & 0,49 \\
Correia transportadora & 188,95 & 0,69 \\
Correia elevadora & $\underline{36.267,92}$ & $\underline{57,07}$ \\
Industrial de manutenção & $32.835,54$ & 90,54 \\
Rodovia & $3.432,38$ & 9,46 \\
Pedágio & $2.681 .066,58$ & 100,00 \\
\hline TOTAL &
\end{tabular}

\section{Análise comparativa entre as rotas 1 e 2}

Nas entradas de energia, por tipo, fonte e forma, nas rotas 1 e 2 - multimodal e unimodal de Rio Verde - GO a Santos - SP, pode-se destacar, na Tabela 4, maior participação de energia do tipo direta para a rota 2 , unimodal. Isto se explica devido ao alto consumo de óleo diesel apresentado pelos bitrens ao longo de um trajeto de $959 \mathrm{~km}$, mesmo a rota 1 , multimodal, sendo maior com $1.375 \mathrm{~km}$.

Destaca-se maior participação de energia do tipo indireta para a rota 1, multimodal. Este fato é representado pelo elevado número de máquinas e equipamentos nos dois transbordos (São SimãoGO e Pederneiras - SP) e na descarga em Santos - SP e pelo alto custo de implantação dos trechos.

Podem-se representar, também, as participações de energia da seguinte forma: rota 1 multimodal $\left(0,34 \mathrm{MJ} \mathrm{km}^{-1} \mathrm{t}^{-1}\right)$ com menor gasto energético, e rota 2 - unimodal $\left(0,50 \mathrm{MJ} \mathrm{km}^{-1} \mathrm{t}^{-1}\right)$ com maior gasto energético. 
TABELA 4. Entrada de energia, por tipo, fonte e forma, em MJ, nas rotas 1 e 2 - multimodal e unimodal de Rio Verde - GO) a Santos - SP. Energy input, by type, source and form, in MJ, for multimodal and one modal transport - routes 1 and 2 -, from Rio Verde (GO) to Santos (SP).

\begin{tabular}{|c|c|c|}
\hline \multirow[t]{2}{*}{ TIPO, fonte e forma } & \multicolumn{2}{|c|}{$\underline{\text { Rotas }}$} \\
\hline & Rota 1 & Rota 2 \\
\hline ENERGIA DIRETA & $2.411 .049,97$ & $2.617 .512,21$ \\
\hline Elétrica & $\underline{47.806,68}$ & $5.510,61$ \\
\hline Tombador hidráulico & $3.025,43$ & $\overline{2.003,86}$ \\
\hline Correia transportadora & $6.806,00$ & $2.003,86$ \\
\hline Correia elevadora & $1.512,39$ & $1.502,89$ \\
\hline Portão eclusa à jusante & 120,69 & - \\
\hline Portão eclusa a montante & 48,28 & - \\
\hline Sugador pneumático & $36.296,90$ & - \\
\hline Fóssil & $2.362 .421,66$ & $2.610 .373,38$ \\
\hline$\overline{\text { Óleo diesel }}$ & $\overline{2.345 .967,74}$ & $\overline{2.587 .281,09}$ \\
\hline Lubrificante & $16.185,25$ & $21.498,78$ \\
\hline Graxa & 268,00 & $1.593,51$ \\
\hline Biológica & 821,63 & $1.628,60$ \\
\hline  & $\overline{821,63}$ & $1.628,60$ \\
\hline ENERGIA INDIRETA & $202.808,14$ & $63.554,37$ \\
\hline Industrial & $\underline{50.390,54}$ & $\overline{27.286,45}$ \\
\hline$\overline{\text { Bitrem graneleiro }}$ & $4.420,82$ & $26.560,45$ \\
\hline Tombador hidráulico & 608,56 & 403,01 \\
\hline Comboio hidroviário & $35.066,06$ & - \\
\hline Portão eclusa à jusante & 19,39 & - \\
\hline Portão eclusa à montante & 19,39 & - \\
\hline Sugador pneumático & 4,33 & - \\
\hline Comboio ferroviário & $9.499,87$ & - \\
\hline Correia transportadora & 562,05 & 134,04 \\
\hline Correia elevadora & 190,13 & 188,95 \\
\hline Industrial de manutenção & 152.417 .60 & $\underline{36.267,92}$ \\
\hline Rodovia & $5.649,49$ & $\overline{32.835,54}$ \\
\hline Hidrovia & $9.822,02$ & - \\
\hline Ferrovia & $136.946,09$ & - \\
\hline Pedágios & - & $3.432,38$ \\
\hline TOTAL & $2.613 .858,11$ & $2.681 .066,58$ \\
\hline $\begin{array}{l}\text { CONSUMO ESPECÍFICO } \\
{\left[\mathrm{MJ} \mathrm{km}^{-1} \mathrm{t}^{-1}\right]}\end{array}$ & 0,34 & 0,50 \\
\hline
\end{tabular}

\section{CONCLUSÕES}

As participações de energia apresentadas na rota 1, multimodal, mostraram que o modal rodoviário foi o que apresentou maior gasto energético, seguido pelo modal ferroviário e modal hidroviário.

Nas participações de energia apresentadas, comparando as rotas 1 e 2, a que apresentou maior gasto energético foi a rota 2, que é unimodal, com um consumo específico de energia cerca de $47 \%$ superior à rota multimodal.

De maneira geral, este estudo foi realizado com o intuito de compreender melhor o consumo de energia utilizado pelos diversos sistemas de transporte, uma vez que existem poucos trabalhos divulgados nesta área. No entanto, há perspectivas melhores no transporte hidroviário e ferroviário. 
Considera-se que este tipo de estudo reflete a necessidade de se buscarem alternativas de transporte diferentes, tais como, a multimodalidade, e mais sustentáveis do ponto de vista energético, ou seja, que possibilitem utilização mais racional de recursos naturais não renováveis, principalmente do óleo diesel.

\section{REFERÊNCIAS}

BORGES. C. Informações sobre custo de implantação de rodovias, hidrovias e ferrovias. Disponível em: <http:// www.cni.org.br/empauta/hidrovia/CESAR_BORGES.pdf>. Acesso em: 4 dez. 2006.

BRASIL. Ministério de Minas e Energia: Balanço energético nacional. Disponível em: <http:// www.mme.gov.br/programs=display.do?chn=88258\&pag=9292>. Acesso em: 13 out. 2006.

BRAVIN, L. F. N. Análise de transporte multimodal na região da hidrovia Tietê-Paraná. 2001. 50 f. Dissertação (Mestrado em Energia na Agricultura) - Faculdade de Ciências Agronômicas, Universidade Estadual Paulista, Botucatu, 2001.

CAIXETA FILHO, J.V.; GAMEIRO, A.H. Transporte e logística em sistemas agroindustriais. São Paulo: Atlas, 2001. 218 p.

CAMPOS, A.T. Balanço energético relativo à produção de feno de "Coast-Cross" e alfafa em sistema intensivo de produção de leite. 2001. 236 f. Tese (Doutorado em Energia na Agricultura) Faculdade de Ciências Agronômicas, Universidade Estadual Paulista, Botucatu, 2001.

COLENCI, R. A. Informações sobre o transporte ferroviário. Entrevistador: Fábio César Bovolenta. Botucatu: Faculdade de Tecnologia, 2006.

COMITRE, V. Avaliação energética e aspectos econômicos da filiêre soja na região de Ribeirão Preto. 1993. 152 f. Dissertação (Mestrado em Planejamento Agropecuário) - Faculdade de Engenharia Agrícola, Universidade Estadual de Campinas, Campinas, 1993.

COPABO. Informações sobre correias transportadoras feitas de borracha. Disponível em: <http:// www.copabo.com.br/index.php/341>. Acesso em: 26 out. 2006.

EIRAS, M. Informações sobre ferrovias e locomotivas da MRS que operam na malha ferroviária Pederneiras - SP/Santos -SP. Entrevistador: Fábio César Bovolenta. Jahu: Faculdade de Tecnologia, 2006.

FIGUEIREDO, K.F.; FLEURY, P.F.; WANKE, P.F. Logística e gerenciamento da cadeia de suprimentos. São Paulo: Atlas, 2003. 483 p.

GRUPO HUBNER. Informações sobre semi-reboques graneleiros de bitrens. Disponível em: <http:// www.grupohubner.com.br/rodolinea/03-bitrem.html>. Acesso em: 7 dez. 2006.

GOODYEAR. Informações sobre massa de pneus. Disponível em: <http:// www.goodyear.com.br/tirecatalog/truck/>. Acesso em: 10 jun. 2006.

IBGE(a). Tabela sobre a safra de soja 2002-2003. Disponível em - www <http:// www.ibge.gov.br/home/estatistica/indicadores/agropecuaria/Ispa/defaulttab.shtm>. Acesso em: 22 jan. 2006.

IBGE(b). Produto interno bruto. Disponível em - www <http:// www.ibge.gov.br/home/presidencia/noticias/noticia_visualiza.php?id_noticia=571\&id_pagina=1>. Acesso em: 15 dez. 2006.

MACHADO, K. Concessões de rodovias: mito e realidade. São Paulo: Prêmio, 2005. 228 p.

MOREIRA, C.R.; GUERRINI, I.A.; BIAGGIONI, M.A.M. Avaliação energética do cultivo de eucalipto, com e sem composto de lixo urbano. Energia na Agricultura, Botucatu, v.20, n.4, p.1-19, 2005 . 
PAVAN, J.L. A comparação dos custos de uma carreta convencional e um bitrem no transporte de soja de Rondonópolis - MT até porto Paranaguá- PR. 2005. 72 f. Monografia (Trabalho de Graduação em Tecnologia em Logística) - Faculdade de Tecnologia, Jahu, 2005.

PINCELLI, K. Informações sobre o terminal graneleiro da empresa do grupo caramuru no porto de Santos - SP. Entrevistador: Fábio César Bovolenta. Jahu: Faculdade de Tecnologia, 2006.

POZO, H. Administração de recursos materiais e patrimoniais. São Paulo: Atlas, 2002. 195 p.

ROMERO, M.G.R. Análise energética e econômica do cultivo de algodão em sistemas agrícolas familiares. 2005. 89 f. Tese (Doutorado em Energia na Agricultura) - Faculdade de Ciências Agronômicas, Universidade Estadual Paulista, Botucatu, 2005.

SAUR EQUIPAMENTOS. Informações sobre tombadores hidráulicos. Disponível em: <http:// www.saur.com.br/principalphp?id_menu=atendimento>. Acesso em: 13 dez. 2006.

SCANIA. Informações sobre cavalo-mecânico que reboca bitrens. Disponível em: <http:// www.scania.com.br/images/espec_tec_r480>. Acesso em: 8 dez. 2006.

TECNOMOAGEIRA. Informações sobre correias transportadoras e correias elevadoras.

Disponível em: <http://www.tecnomoageira.com.br/contato_index.asp?language=br>. Acesso em: 14 dez. 2006. 